De cómo en el fragor de la batalla el entrometido dijo «hablemos» y por qué rara razón ...

\title{
DE CÓMO EN EL FRAGOR DE LA BATALLA EL ENTROMETIDO DIJO «HABLEMOS»Y POR QUÉ RARA RAZÓN LOS CONTENDIENTES, BRAZO EN ALTO, DETUVIERON EL GESTO Y EL ARMA PARA ESCUCHARLE / NO ES CINE PARA HOMBRES
}

\author{
ABOUT HOW, IN THE HEAT OF BATTLE, A MEDIATOR SAYS «LET'S TALK \\ ABOUT IT!» AND, FOR SOME STRANGE REASON, THE COMBATANTS, \\ ARMS RAISED TO FIGHT, DROP THEIR POSTURE AND THEIR WEAPONS TO \\ LISTEN - THIS IS NO MOVIE FOR MEN
}

Eloy FERNÁNDEZ PORTA

Universidad Pompeu Fabra eloi.fernandez-porta@upf.edu

Resumen: El presente texto se sumerge en diversas obras cinematográficas, de ficción y documentales, principalmente, pero también musicales, sociológicas, fotográficas, filosóficas, teatrales, mediáticas..., para poner de manifiesto la subjetividad -masculina-que habita en ellas. El decir del hombre hoy; el decirse y actuar como hombre hoy es diferente al decirse hombre y actuar como tal hace dos, tres o más décadas. El resultado, dice el presente texto, es un mundo vaciado de sustancia masculina.

Palabras clave: subjetividad, género, masculinidad, mediación, cuerpo.

Abstract: This text focus on various cinematographic works documentaries, and films principally, but also musicals, sociological studies, photographic montage, philosophical works, theater, and news -to highlight the masculine subjectivity that inhabits them-. Talking like a man today, calling oneself a man, and acting like a man, is different today than calling oneself a man, and acting as such, two, three or more decades ago. This text, this author, claim the current world is emptied of masculinity.

Keywords: Subjectivity, genre, masculinity, mediation, body. 
y hete aquí que, sin previo aviso -no se hizo constar en ningún cartel de ninguna taquilla de ninguna sala de cine, como sí se hizo cuando Terrence Malick presentó aquel filme soporífero, una dosis masiva de orfidal, obligando con ello a numerosos directores de sala a colgar un rótulo prometiendo al espectador la devolución del coste de la entrada si después de media hora de proyección sentía que el tedio le vencía, lo que ocurrió no pocas veces, el personal, los actos, la horda más bien, dejó de apuntarse con sus rifles, disparar con puntería, acertar al jinete de un caballo al galope y, en sus bruscos remedos de diálogo, recurrir al acervo lingüístico del Capitán Hadoock o a las variantes innumerables sobre el vocablo «fuck». El bulldozer calló y los milicianos emboscados que escrutaban, ansiosos, el cielo, esperando bengales y misiles, solo vieron nueves, hilachas de cumolunimbus, desplazándose perezosas a lo largo de la mañana dominical. A insultó; B no replicó. C mentó a la madre; D renunció a aludir a la hermana. El traficante de blancas perdió los nervios, la poquita templanza que Dios le dio; al otro lado de la mesa de juego, el otro mafioso, secundado por una recua de guardaespaldas, bajo la bombilla de 40 wattios, se contuvo, británico en New Jersey, gentleman en Moscú, diplomático, entre olivos y trabucos, en la Sicilia profunda.

En la banda de heavy metal, en un ensayo interrumpido por un cuádruple desacuerdo, el batería aprovechó un receso en la Madre de Todos los Broncazos, marcó un número y a los treinta minutos comparecía, en las instalaciones de la discográfica, donde nunca se había visto a nadie con el pelo corto, un cincuentón con peinado a tazón y jersery a listas verticales de colores. Recién llegado, entre guitarras, bajos y metros de cableado y empalmes sobrecargados, metáfora del embrollo laberíntico en que se hallaban, varados, los cuatro músicos, hartos de sí mismos, y tan rabiosos y airados, a su edad, como se habían mostrado en sus canciones primerizas - años hacía que, desde su lejana Juventud Sin Esperanza ${ }^{\circledR}$, que no tenían, compartida, esa sensación, ese pálpito que une a un grupo para siemprese puso a hablar, en tono pusilánime pero extrañamente seguro, «hablémoslo», «los problemas son como los colores: hay una gradación, ¿veis?, hay matices, hace falta pasar del gris perla al gris claro y de ahí...», qué rayos dice el andoba este, con acento de Brooklyn en plena Bay Area de San Francisco, sobre ejercicios de respiración, métodos de crítica constructiva, y prescribió a cada miembros de la banda en descomposición un deber escolar, de los tiempos del show and tell y la comida preparada por la madre en tuperbar: redactar meditadas listas de objeciones a sus compañeros, que siempre debían incluir, como matiz respetuoso, un reconocimiento del mérito ajeno. Un NO mayor y un sí menor, como propuso George Grosz, para ir empezando, en el prefacio de un tratamiento - ¿nosotros, en tratamiento?- que se preveía más largo que el más extenso de sus discos, acaso, quien sabe, el análisis interminable que Freud enunció en uno de sus textos clave sobre las ciencias de la psique, no digáis luego que no estabais avisados.

No cabía la menor duda: el chiflado del bataca había contratado, sin consultar -sin ponerlo en común, en un concilio igualitario-, a un psicólogo, no a uno de esos jóvenes que en la primera sesión 
propone ir todos juntos a patinar por el parque, lo que pudieran haber aceptado aun a regañadentes, aunque solo fuera porque el monopatín lo dominaban desde antes de componer sus primeras canciones en el garaje, y los skateboards que recorren el asfalto global están decorados con logos de la banda y con macabras y exactas pegatinas de su dibujante oficial, el mítico Pushead. Nada de eso: a goddamn shrnik, un loquero, un matasanos de la cosa de la psiquis, tres higas al doctor, la institución médica en persona y, por si fuera poco, con el jersey en pleno inicio de la primavera. Todos se preguntaban cuándo se torció todo, en qué punto de su carrera fulgurante, el catasterismo a los cielos del rock, las estatuas de cera, el Salón de la Fama como una extensión del primer piso de sus respectivos casoplones, todos aquellos términos que venían usando, desde los días del garaje y las más justificadas pellas que jamás se hayan dado en el sistema de la educación secundaria, «la Institución», esa palabra mágica que, regurgitada por ellos, con voz de cazalla, sobre el trasfondo de un punteo de bajo, esa palabra que siempre había despertado la pasión de sus fans adolescentes, que la coreaban en los estadios, repletos -no basta con ser mundialmente famoso para ser una banda de estadio, y ellos lo fueron, quizá aún lo son, por antonomasia-, así como en festivales, en la complicidad de los garitos y, botando y botando sobre la cama, en el cuarto de casa de sus padres, la Institución, esa entidad imaginaria, ese factor de oposición que el artista siempre necesita para acabar de convencerse de que él es la Libertad y la da a manos llenas, estaba allí, en carne y hueso avejantados, se había hecho presente y apartaba un bajo sin pedir permiso, tanteaba el terreno buscando un espacio libre en el cafarnaún del estudio y, a falta de sofá o diván, que debían ser sus muebles predilectos, el muy canalla va y se sienta en el taburete del batería, decididamente están conchabados, con su aquiesciencia y su salmodia, como diciendo, con su falsa relajación corporal, «no sois los autores de Ride the Lightning, ni siquiera los de Seek and Destroy: sois un caso de estudio, un pack de pacientes».

Y su salmodia, la misma, lo notaron, que debía haber oído, el día anterior, el broker estresado, la que escucharía con alivio la abogada vegana, era la canción en prosa de la Conciliación, el spoken word del 'aquí todos somos amigos' (que no «coleguillas»: no entraba ese término en el manual de su jerga clínica) y la balada pop autotuneada del reencuentro y la mano tendida. ¿Tan bajo habían caído, se preguntaban al unísono, sin palabras, sin que el cantante hallara fuerzas para expresar, como siempre había hecho hasta entonces, el descontento y el NO? Su disco más reciente, que no era, lo admitían, el mejor de su carrera, ¿había sido de veras tan malo como para provocar, junto con otros problemas larvados que solo afloran cuando baja la cuenta de resultados, la deserción de uno de sus miembros, a quien pugnaban sin éxito por encontrar sustituto? ¿Aquí, a esa sala imposible, les habían llevado veinte años de turbulenta carrera basada en la gestión y expresión sonora, a voz en cuello, del ámbito emocional que la Teoría Ilustrada de los sentimientos definiera, desde Adam Smith, como «los sentimientos inmorales»? ¿Tantos riffs y tan elaborados solos y tanto sindiós y culto a Baco y otras divinidades menos nobles en el backstage - «las giras de las bandas», escribía Sabino Méndez, «son exactamente como la gente se las imagina»-para acabar así, en las manos blandas del sinsutancia ese de las rayas verdes, azules, ni una negra, el que jamás consideró ponerse una camiseta de su grupo? Seguro que su hijo vestía igual. Seguro que nunca había oído hablar de Metallica. 
¿Qué hacía allí ese entrometido, the univited guest, el espectro de Banquo en el banquete de los reyes del metal? ¿Desde cuando las nobles, viriles querellas entre hombres requiren de un metomentodo con título universitario, un producto de las escuelas de psicología o autoayuda pagada, si es que hay diferencia? ¿No le habían contado al rayitas que cuando dos se enzarzan quien se mete por medio es el que cobra? ¿Quién le había dado vela en lo que parecía ser, en aquellos días, el entierro a cámara negra, terrible pero solemne como todos los funerales, de un grupo que representaba por sí solo, un género musical entero, el de la ira de las periferias y la rabia de los pueblos norteamericanos que no son pueblos, solo un escalextric de carreteras elevadas y un centro comercial y, con ellos, por qué no, el del pijerío internacional que, por turismo de clase, por esnobismo, porque las escasas y tan criticadas baladas del grupo se habían convertido en la banda sonora de sus encuentros eróticos y amorosos, pero también, no puede pasarse por alto, porque en sus holgados apartamentos lo sentían $y$ lo vivían como cualquier otro oyente, y mejor que la mayoría de los vecinos de la Bay Area? ¿Acaso el batera, con su excéntrica afición, cultivada desde que les llegó, a edad temprana, el éxito mundial, por llenar su mansión angelina con pinturas y esculturas de alto copete, de artistas renombrados, que sus compañeros quisieron entender, comprensivos, como otra forma excéntrica del derroche, como coleccionar Chryslers o marcharse, así el cantante, una vez al año, a la estepa rusa, provisto con un fusil y orientado por un guía local - ese sí era un buen guía: simple, monosilábico, analfabeto en inglés y posiblemente en su propio galimatías cirílico, fumador compulsivo, a veinte grados bajo cero, de tabaco negro que liaba en minúsculos cigarrillos- para abatir osos -la foto de su cuerpo corpulento, la bota comprada en WallMart sobre el lomo de la bestia derrumbada, la sangre sobre el hielo, flujo rojo y flujo blanco, como en la imagen de la cubierta del disco que motivó el inicio de su larga crisis-, con la coartada de estar llevando a cabo el enésimo acto de rehabilitación de alcohol? ¿Acaso se había convertido, óleo a óleo con la nefasta influencia de los marchantes y galeristas, sacacuartos, en un ser refinado, un dudoso proyecto de dandy que pugnaba por salir y crecía bajo sus pintazas de rockerazo cuarentón, aun empeñado en seguir vistiendo, con bermudas y deportivas, como el churumbel de high school que, pobre como una rata, en vez de descargar sus discos o escucharlos o Spotify, por pura devoción, logia de la Hermandad del Metal, acudía a tiendas retro para poder adquirirlos en vinilo o incluso en cedé? ¿Que fue del fuck you all y del good night motherfuckers? ¿Qué de los desplantes con la prensa y de las avalanchas provocadas en salas de conciertos al negarse a tocar un bis y hacer mutis sin despedirse porque yolovalgo. ¿Qué se fizo?

- It's not a world of man aymore, I tell you. It's a world of office clerks, bureaucrats, clockwatchers. No adventure to it!

Un mundo que requiere de asesores, prótesis, profes venidos de plácidos campus privados en un mundo vaciado de sustancia masculina. Así lo expresaba Tony Roma, el salesman, el vendedor agresivo - pura agresividad para vender sus viviendas sobre plano. Vaciado. Un proceso que no solo afecta al sorprendente documental sobre la caída y auge de los Dioses del Heavy, sino que se extiende a todos aquellos géneros cinematográficos masculinizados. Cine bélico sin escena de batalla -solo concilios en despachos del búnker, encuentros entre cónsules. Pelis de acción con muy pocas hostias 


\section{Tropelías. Revista de Teoría de la Literatura y Literatura Comparada, 31 (2019) \\ De cómo en el fragor de la batalla el entrometido dijo «hablemos» y por qué rara razón ...}

y un número contado de tiros - qué lejos quedan los días en que Rambo fundía a 143 norvietnamitas en una de sus excursiones a la guera inacacada. Afteraction movies, las llamó Antonio Weinrichter en referencia al cine neo-noir de los años setenta-, y ese modelo que empezó siendo experimental y minoritario, se ha trasladado al mainstream. Es la línea que sigue Tarantino, sobre todo en su primera época y más que nunca en Pulp Fiction, donde logra que, de entre todos los personajes que se disputan la atención del espectador, el boxeador, los sicarios, la novia del gánster, la pareja de atracadores aficionados, el picoleto violador y el psicópata sudista de la tienda de armas, el más memorable sea, contra toda previsión, quien menos habla y más resuelve, el hombre-solución, el expeditivo e impecable diplomático del crimen interpretado, con cortesana elegancia, no sin retranca, por Harvey Keitel. Más: dramas político-policiales sobre el antes llamado Problema Vasco y la ETA en que el comisario, el etarra y el confidente pasan a ser persones secundarios, y el tono de Spanish movie de serie B desaparece para dar lugar a un documental, o a una docuficción verosímil, en que el centro de la escena lo ocupa, trajeado, mesurado, dotado de un maletín y de ese cincismo pragmático que forja la vivencia distante de la brutalidad recíproca, Él: el mediador.

Mediadores, solucionadores, negociadores: así como Xabi Alonso, en su día, fue, en la Guardería Nacional, el único bastión de la sensatez y el hablémoslo -el único que hablaba como una persona aldulta, como podría comprobarse en cada entrevista, al menos antes de que Piqué, que mientras quiso o cuando le convino fue un adulto, se conviertiera en Piqué y limitara sus tareas de mediación a intermediar entre sí mismo y sus redes sociales-, el guardián de la palabra en esa caterva de adefesios vigoréxicos cuya idea de la inteligencia emocional se podía reducir, por lo general, a un espaldarazo violento o a una partida de mus para aliviar tensiones, arrastro, canto las cuarenta, qué vas a cantar tú perillán, si no cantas más que rap en inglés guachi-guachi, que nos tienes fritos poniendo cada día el patatín-patatán de los negratas en el radiocasé del vestuario. Fritos, y vas de farol, que las cuarenta ya las tienes, y te vas a llevar más leches que tu número de dorsal, que es de dos cifras y es alto porque eres suplente y suplente serás, asimilao, acopladillo, que todos sabemos que al míster, que pierde aceite, le haces tilín con tu melenitta de efebo y tus aires de moderna, piazo julandrona, déjate ya de faroles que saca el rey de copas, que lo llevas de mano, de salida.

De salida, pues.

Para cada vecino secuestrado, un negociador; para cada capomafias, un psiquiatra. El racista discapacitado tendrá un cuidador africano con el cual bastan dos escenas del tráiler, ya esta visto, irá desarrollando, el grunón del Frente Nacional con corazoncito, lenta y paulatinamente un vínculo sanador, y la bestia etnicista será convertida, por las artes mágicas de la comedia, en cursilón sobrevenido, a buenas horas: un anciano que, como mandan los cánones de la psicología conductista y de la poesía mala, se reconecta con recuerdos de infancia -cuánta poesía sobre memorias infantiles, qué tróspida toda, qué turra con el solete aquel de la niñez y cuántas razones para el panfleto Contra los poetas de Witold Gombrowicz, corto le quedó. ¿Un misántropo? Su enfermera. ¿Un crítico de música amargado, con perdón de la redundancia? Una fan ingenua y sincera, de pelo claro y mirada limpia, que con su bendida inocencia le hace recordar cómo fue que años antes de las reuniones con 
directores de festivales, antes de los pactos y componendas con empresas discográficas, cuando aún no se había acostumbrado a redactar reseñas laudatorias que ni el más primerizo de sus jóvenes lectores se cree, decidió, bendita juventú, su vida en la música: no en su industria ni en sus sucias cañerías, sino en la pura emoción de esas canciones en que, como señaló José María Conget, brilla «lo olvidable, pero no olvidado».

- «¿Negociar? -se pregunta, retórico, el vendedor Roma. «Pero negociar el qué?» En la retórica del hardselling no hay concesión, ni debate, ni dialéctica: su argumentatio es pura afirmación, impositiva: abrumar con promesas y visiones de futuro al primo de turno para lograr que los cuatro dólares que tiene ahorrados los invierta en una propiedad de futuro más que dudoso. Nadie negoció nada con Roma, su vida laboral fueron órdenes, amenazas y la zanahoria de un bonus por una venta extra, así que ¿por qué iba a hacerlo él? ¿Con qué instrumentos? Si tuviera tiempo, entre venta y venta, para ir al cine, Roma exclamaría, cerveza en mano y con cubo de palomitas gigante, manspreading, «¡No es un cine para hombres! Son solo películas sobre funcionarios del Acuerdo, burócratas el Pacto, gentecilla que no tolera que se diga una palabra más alta que otra: relojeros que solo se dedican a coordinar al segundo los tiempos distinto de personas diferentes», como hacía el artista cubano Felix González-Torres en su fotografía Perfect Lovers (1991), la obra icónica del amor gay en la era del sida, statement para el reconocimiento y para la coordinación -cuatro nociones con las que Roma tiene problemas, y para las que usa nombres bien distintos a los que acabamos de emplear-.

¿Cómo interpetar el reciente y creciente protagonismo del personaje al que nos referimos, con sus múltiples facetas? En términos de teoría del personaje ficcional, habrá que verlo como una revolución, o como una versión menor del impulso revolucionario. Es la que soñaba en voz alta, en su único monólogo, un crítico teatral llamado Moon, a quien su propio papel, secundario, en el mundo de las tablas, le habían inspirado una singular versión de La Internacional:

Sueño con [...] una armada de ayudantes de diputados, los segundos de a bordo, los maletillas, los meritorios, los mano derecha, echando abajo las puertas de los palacios donde el segundo hijo ya se ha encaramado al trono habiendo cometido regicidio con un palo de críquet. ¡Vosotros, los piernas del mundo, levantaos!

En la rebelión imaginada por Moon, el caso de Keitel no sería una excepción: nos llevaría a imaginar una nueva Historia de las Artes Escénicas en que el protagonista de Edipo Rey, y el de todas las tragedias, sería el Corifeo; Hamlet cambiaría su título y se llamaría Horacio; a Nora la recordríamos vagamente, como la figurante de una pieza llamada Krogstad; la escena culminante de la obra ibseiana no sería aquella en que la mujer, saliendo de casa, tomando el abrigo, le hace saber a su esposo que no puede pasar la noche bajo el techo de un extraño, sino otra anterior, en que el abogado, el jurista justo, la tranquiliza diciendo: «Todo puede arreglarse amistosamente».

\footnotetext{
${ }^{1}$ Tom Stoppard, The Real Inspector Hound, 1969. Traducción propia. Ante la imposibilidad de dar una traducción literal de la frase, he optado por la expresión, «ser un piernas», que, aunque algo desusada, puede concentrar el sentido de los distintos personajes cuyas tareas complementarias se enumeran en el monólogo.
} 


\section{Tropelías. Revista de Teoría de la Literatura y Literatura Comparada, 31 (2019) \\ De cómo en el fragor de la batalla el entrometido dijo «hablemos» y por qué rara razón ...}

189

¿Amistosamente? ¿Un matrimonio que ya había naufragado, mucho antes del primer acto, y solo la cobardía del marido, y su amor a la convención, impedía deshacer formalmente? Difícil creerlo... Más sentido cobra, sin duda, en la versión stopparddiana del drama del príncipe danés, donde esta entrada de diálogo, remite inevitablemente, a su primera pieza, Rosencranz y Guildernstern están muertos, estrenada dos años antes, y donde los amigos de Hamlet, de nombre intercambiable, toman el centro de la escena, con resultados que, si no propiciaron la revolución en la corte de Elsionre, sí removieron los cimientos del teatro de texto de los sesenta al renovar la faceta metaficcional que procedía de Pirandello por medio de una inflexión metalingüística y una comicidad letrada que rompe con el código existencial del metateatro al uso. Pero, ¿y Edipo? ¿Nos avendremos a un Edipo de buen rollito, Edipo el consorte sin suerte o, en producción exclusiva del Comedy Channel, Oyes Edipo, déjeme un momentín el cuchillo ese que traes, que me viene al pelo para cortar unas rebanadas; si vamos a hacer un intercambio de parejas, ¿no será con el estómago vací, no? Digo yo, vamos... Y no me mires así, que los intercambios siempre pasa lo mismo: al principio es todo jopé jopé y en un rato ya ves como es ijoder! ijooooooder!»

¡Ni siquiera Deleuze y Guattari, con su minuciosa deconstrucción del mito freudiano, se habían atrevido a tanto! Ambos pusieron en cuestión la centralidad de «la novela familiar» en la constitución del sujeto, y supieron recriminar a los psiquiatras que, al interpelar al niño, sobre cualquier tema, lo hicieran siempre como diciendo «iresponde papá-mamá cuando te hablo!». Pero ni esas ideas ni su defensa o invención de un sujeto rizomático y una colectividad como agenciamiento les impidieron reconocer la existencia de lo edípico como construcción o incluso como sustrato: simplemente le dieron mucha más importancia, y menos protagonismo en la arquitectura psíquica, de la que le concedió el maestro vienés. Si Edipo televisivo, en plano medio y con risas enlatadas, mantiene una saludable one-night-stand con una MILF, si años antes se pasó de frenada en una curva y se comió al coche que venía de frente, torpe de mí, espero que no haya cámaras, creo que no se ha coscado nadie... ¿dónde está la tragedia, el drama siquiera?

La deriva de los géneros masculinizados del Séptimo Arte hacia las temáticas de la intercesión y el acuerdo trae consigo un movimiento desde el drama hacia la comedia. Viene con él un giro desde la introspección existencial hasta el gag físico, y una cierta trivialización, un animus burlesco. Trivializar, sí, pero no en el sentido de negarle a un tema la importancia que merece, sino más bien en el doble significado, introducido por Eliot en un verso famoso, «enséñame a que me importe y enséñame a que no me importe». En el segundo de esos sentidos, sobre todo. Porque cuando se trata de la sexuación, nos han enseñado bien su importancia, sus importunas importancias: afectiva, psicológica, social, política, étnica, de clase, iconográfica, dialogal.... De ser cierto, como sostiene la tradición lacaniana, que el sexo constituye un vacío en la cadena simbólica, lo primero que cabría decir sobre él, la única sustancia del vacío, es que importa: es relevante y, por ello, trae al sexo todo aquello que parecía quedar fuera de él, es un importador incansable de significados; sentidos, índices, ideas y nociones se acumulan en los almacenes de sus aduanas, y no hay equipo de agentes que pueda hacerse cargo de todos ellos y distribuirlos: acaso aún no sepamos lo suficiente, pero es seguro que al 
enseñarnos sobre la sexuación, y al enseñar nosotros a otros, por vía teórica o práctica, su importancia la hemos destacado, por encima de cualquier otra de sus cualidades, con saña.

Aprobamos con nota la parte del examen sobre la importancia; en cambio, cuando llega la parte de «enséñame a que no me importe»... ahí pincha casi todo el mundo. Acaso los post-millenials pinchen en hueso algo menos que la generación anterior, quizá haya algo de evolución histórica, pero esta prometedora hipótesis positivista parece quedar muy en entredicho cuando observamos, en los modos de autoexposición y comentario de la esfera digital, que cuanto menos complicado resulta conseguir una relación más pública se vuelve, y «publicidad» implica juicio, evaluación, aquilatamiento, cuestionamiento, y en la red todo el mundo está invitado a participar de ese jurado popular -es poco menos que obligatorio... Pero quizá «follarse a tu jefe no es para tanto», como declaraba, en una salvífica entrada en su blog, la escritora Ainhoa Rebolledo. En la misma línea se situaba el célebre número musical en que Miley Cyrus, por una vez atinada en su tan comentado devenir-mujer, hacía que uno de sus comparsas se pusiera una máscara de Hillary Clinton y, transmutada de pronto en Monica Lewinski, simulaba practicarle una breve felación, entre verso y verso de una canción, volviendo a la tonada en cuestión de minutos. Pocas veces, en el ámbito de la cultura de masas y fuera del terreno acotado de la comedia, ha logrado alguien enseñar a los demás a que no les importe. Porque Cyurus, de quien nunca escuché una canción entera, ni entra en mis planes hacerlo, pareció lograr con ese gesto en cuclillas lo que años de contraeducación sexual no habían conseguido: afirmar que, a pesar de todos los pesares - a pesar de la visión weberiana del sexo como jerarquía, de la ridícula codificación iconográfica de la felación como si se tratase de acto de sumisión«en un acto de sexo oral, ¿quién es activo y quién es pasivo?», se preguntaba, con toda razón, JosepVicenç Marqués-, a pesar de las importancias ético-jurídico-macropolíticas que la prensa se empeñó a conferir a ese momentáneo desahogo mutuo - a pesar, también, de la evidencia palmaria de que la superioridad jerárquica en el ámbito laboral no se traduce necesariamente en un poder superior en el terreno del sexo-, a pesar de todo... sí, hay un punto, un aspecto, una faceta en que, verdaderamente, no importa. Feliz de quien logre admitirlo; más feliz aún quien lo asuma, no ya en su ideario sino en su cuerpo, que, bien lo sabemos, no siempre sigue los dictados del anterior. 